\title{
Hypercortisolism and primary aldosteronism caused by bilateral adrenocortical adenomas: a case report
}

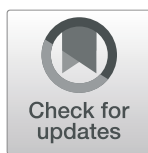

Kaiyun Ren ${ }^{1}$, Jia Wei', Qilin Liu', Yuchun Zhu², Nianwei Wu², Ying Tang ${ }^{3}$, Qianrui Li', Qianying Zhang ${ }^{1}$, Yerong Yu', Zhenmei $\mathrm{An}^{1}$, Jing Chen ${ }^{4}$ and Jianwei Li ${ }^{1 *}$

\begin{abstract}
Background: Co-existing Cushing's syndrome and primary aldosteronism caused by bilateral adrenocortical adenomas, secreting cortisol and aldosterone, respectively, have rarely been reported. Precise diagnosis and management of this disorder constitute a challenge to clinicians due to its atypical clinical manifestations and laboratory findings.

Case presentation: We here report a Chinese male patient with co-existing Cushing's syndrome and primary aldosteronism caused by bilateral adrenocortical adenomas, who complained of intermittent muscle weakness for over 3 years. Computed tomography scans revealed bilateral adrenal masses. Undetectable ACTH and unsuppressed cortisol levels by dexamethasone suggested ACTH-independent Cushing's syndrome. Elevated aldosterone to renin ratio and unsuppressed plasma aldosterone concentration after saline infusion test suggested primary aldosteronism. Adrenal venous sampling adjusted by plasma epinephrine revealed hypersecretion of cortisol from the left adrenal mass and of aldosterone from the right one. A sequential bilateral laparoscopic adrenalectomy was performed. The cortisol level was normalized after partial left adrenalectomy and the aldosterone level was normalized after subsequent partial right adrenalectomy. Histopathological evaluation of the resected surgical specimens, including immunohistochemical staining for steroidogenic enzymes, revealed a left cortisol-producing adenoma and a right aldosterone-producing adenoma. The patient's symptoms and laboratory findings resolved after sequential adrenalectomy without any pharmacological treatment.
\end{abstract}

Conclusions: Adrenal venous sampling is essential in diagnosing bilateral functional adrenocortical adenomas prior to surgery. Proper interpretation of the laboratory findings is particularly important in these patients. Immunohistochemistry may be a valuable tool to identify aldosterone/cortisol-producing lesions and to validate the clinical diagnosis.

Keywords: Bilateral adrenal adenomas, Primary aldosteronism, Hypercortisolism, Adrenal venous sampling, Histopathology

\section{Background}

The human adult adrenal cortex is composed of the zona glomerulosa (ZG), zona fasciculata (ZF), and zona reticularis (ZR), which are responsible for production of mineralocorticoids, glucocorticoids, and adrenal androgens, respectively [1]. Primary aldosteronism (PA) and

\footnotetext{
*Correspondence: jerryli678@yahoo.com

1 Department of Endocrinology and Metabolism, West China Hospital,

Sichuan University, Chengdu 610041, China

Full list of author information is available at the end of the article
}

Cushing's syndrome (CS) are usually caused by autonomous over-secretion of aldosterone or cortisol, from the corresponding adrenal zones as a result of hyperplasia or tumors. Both overt and subclinical PA and CS have long-term adverse effects on multiple organs $[2,3]$. Patients with concurrent hypersecretion of cortisol and aldosterone have been previously reported, and it is difficult to make the correct diagnosis in those patients [4-8], however, most of these patients had adenomas that secreted both cortisol and aldosterone simultaneously, i.e.

(c) The Author(s). 2019 Open Access This article is distributed under the terms of the Creative Commons Attribution 4.0 International License (http://creativecommons.org/licenses/by/4.0/), which permits unrestricted use, distribution, and reproduction in any medium, provided you give appropriate credit to the original author(s) and the source, provide a link to the Creative Commons license, and indicate if changes were made. The Creative Commons Public Domain Dedication waiver (http://creativecommons.org/publicdomain/zero/1.0/) applies to the data made available in this article, unless otherwise stated. 
aldosterone- and cortisol-co-secreting adrenal tumors. Patients with bilateral adenomas that independently secrete different hormones are extremely rare. Herein, we report a patient with co-existing cortisol-producing and aldosterone-producing adrenocortical adenomas, one in each adrenal gland. The diagnosis was initially made by adrenal venous sampling (AVS) and subsequently validated by postoperative pathology findings. Additionally, we reviewed similar cases reported to summarize the diagnosis and management of this disorder.

\section{Case presentation}

A 30-year-old Chinese male was admitted to the local hospital with a history of intermittent muscle weakness for over 3 years. He was found with high blood pressure (170/ $118 \mathrm{mmHg})$, hypokalemia $(2.0 \mathrm{mmol} / \mathrm{L})$, normal thyroid function, and bilateral adrenal masses on computed tomography (CT). He had no history of alcohol or drug abuse, in particular, no history of steroid usage, and no family history of endocrine diseases or malignant tumors. $\mathrm{He}$ was treated with a temporary prescription of nifedipine, potassium chloride controlled release tablets, and was referred to our hospital for further investigation.

Upon admission to our hospital on August 11, 2016, physical examinations revealed blood pressure of 153/ $100 \mathrm{mmHg}$ and pulse rate of 76 beats per minute. His body mass index was $29.1 \mathrm{~kg} / \mathrm{m}^{2}$, height $176 \mathrm{~cm}$, weight $90 \mathrm{~kg}$, and waist circumference $98 \mathrm{~cm}$. There were no specific findings on chest or abdominal examination and his muscle power was normal. No edema of the lower extremities was noted and he had no Cushingoid features (i.e., moon face, purple striae, or hirsutism) except slight central obesity.

Routine laboratory tests revealed an extremely low serum potassium $(2.12 \mathrm{mmol} / \mathrm{L})$ with relatively high urinary potassium $(38.66 \mathrm{mmol} / 24 \mathrm{~h})$. Twenty-four-hour urinary free cortisol was $140.7 \mu \mathrm{g}$ and $137.7 \mu \mathrm{g}$ on two separate occasions (reference range: 20.26-127.55 $\mu \mathrm{g} / 24$ h). Detailed relevant biochemical and endocrinological findings are shown in Table 1. His aldosterone-to-renin ratio (ARR) was within normal range after discontinuation of nifedipine for more than 2 weeks, when druginduced false-negative results were likely eliminated. Thus, further screening for PA was not performed (Table 2) [9]. In overnight and standard low-dose dexamethasone suppression tests, dexamethasone failed to suppress endogenous cortisol secretion, indicating CS (Table 3). Adrenal CT scan revealed one round, homogeneous, low-density mass in each adrenal gland. The mass on the right was $19 \times 14 \mathrm{~mm}$ while the one on the left was $25 \times 15 \mathrm{~mm}$ (Fig. 1). Bilateral AVS was performed to lateralize the functional side. Concentrations of plasma

Table 1 Laboratory characteristics

\begin{tabular}{|c|c|c|c|c|}
\hline & Upon admission & After left partial adrenalectomy & After right partial adrenalectomy & Reference values \\
\hline WBC $\left(10^{9} / L\right)$ & 7.22 & 6.75 & - & $3.5-9.5$ \\
\hline $\mathrm{Hb}(\mathrm{g} / \mathrm{L})$ & 143 & 151 & - & $115-150$ \\
\hline Plt $\left(10^{9} / L\right)$ & 205 & 249 & - & $100-300$ \\
\hline Glu (mmol/L) & 4.06 & 3.98 & 4.95 & $3.9-5.9$ \\
\hline ALT (IU/L) & 45 & 28 & 52 & $<50$ \\
\hline AST (IU/L) & 27 & 18 & 31 & $<40$ \\
\hline Cre (umol/L) & 49.0 & 51.0 & 73.0 & $37.0-110.0$ \\
\hline $\mathrm{BUN}(\mathrm{mmol} / \mathrm{L})$ & 3.90 & 2.50 & 5.20 & $3.13-8.17$ \\
\hline LDL-C (mmol/L) & 2.35 & 2.79 & 2.63 & $<4.0$ \\
\hline TG $(\mathrm{mmol} / \mathrm{L})$ & 2.20 & 3.33 & 1.96 & $0.29-1.83$ \\
\hline $\mathrm{K}(\mathrm{mmol} / \mathrm{L})$ & 2.12 & 1.98 & 4.68 & $3.5-5.3$ \\
\hline $\mathrm{Na}(\mathrm{mmol} / \mathrm{L})$ & 142.9 & 144.0 & 140.0 & $137.0-147.0$ \\
\hline HbA1c (\%) & 5.1 & - & - & $4.5-6.1$ \\
\hline Plasma norepinephrine (ng/L) & 180 & - & - & $174-357$ \\
\hline Plasma epinephrine (ng/L) & 86 & - & - & $60-104$ \\
\hline Urinary norepinephrine ( $\mu \mathrm{g} / 24 \mathrm{~h})$ & 30.97 & - & - & $16.3-41.5$ \\
\hline Urinary epinephrine ( $\mu \mathrm{g} / 24 \mathrm{~h})$ & 5.15 & - & - & $7.5-21.9$ \\
\hline Urinary free cortisol ( $\mu \mathrm{g} / 24 \mathrm{~h})$ & $\begin{array}{l}140.7 / \\
137.7\end{array}$ & - & - & $20.26-127.55$ \\
\hline Urinary K (mmol/24 h) & 38.66 & - & - & - \\
\hline
\end{tabular}

$A L T$ alanine aminotransferase, AST aspartate transaminase, BUN blood urine nitrogen, Cre creatinine, Glu glucose, $H b$ hemoglobin, $H b A 1 c$ glycosylated hemoglobin, $K$ kalium, LDL-c low-density lipoprotein cholesterol, Na natrium, Plt platelet, TG triglyceride, WBC white blood cell count 
Table 2 Results of the ARR tests, saline infusion test and captopril challenge test

\begin{tabular}{|c|c|c|c|c|}
\hline & & $\begin{array}{l}\text { PRA } \\
\text { (ng/ml.h) }\end{array}$ & $\begin{array}{l}\text { PAC } \\
(\mathrm{ng} / \mathrm{dl})\end{array}$ & $\begin{array}{l}\text { ARR } \\
\text { (ng/dl:ng/ml.h) }\end{array}$ \\
\hline Before operation & & 2.03 & 25.90 & 12.76 \\
\hline \multirow[t]{4}{*}{ After left partial adrenalectomy } & Before saline infusion & 0.49 & 34.79 & 71.00 \\
\hline & After saline infusion & 0.70 & 26.94 & 38.49 \\
\hline & Before captopril challenge & 1.89 & 35.38 & 18.72 \\
\hline & After captopril challenge & 1.42 & 31.17 & 21.95 \\
\hline After right partial adrenalectomy & & 5.04 & 13.81 & 2.74 \\
\hline
\end{tabular}

PRA plasma renin activity, $P A C$ plasma aldosterone concentration, $A R R$ aldosterone-to-renin ratio

aldosterone and cortisol were measured in specimens from both adrenal veins (AV) and the inferior vena cava (IVC), and corrected by concentration of plasma epinephrine. As shown in Table 4, epinephrine concentrations in both AVs were approximately 10-fold higher than that in the IVC, suggesting successful adrenal venous catheterization. Notably, at $>200 \mathrm{ng} / \mathrm{dL}$, the aldosterone concentration in the right adrenal vein was markedly higher than those in the LAV and the IVC, suggesting excess secretion of aldosterone from the right adrenal mass. Additionally, $7701 \mathrm{nmol} / \mathrm{L}$, the cortisol concentration in LAV was 12.81-fold higher than that in the RAV and 27.4-fold higher than that in the IVC, suggesting excess secretion of cortisol from the left adrenal mass. Thus, with AVS, hypersecretion of cortisol from the left adrenal tumor and that of aldosterone from the right tumor was identified.

\section{Treatment and follow-up}

A sequential partial adrenalectomy (laparoscopic left partial adrenalectomy followed by endoscopic right partial adrenalectomy) was performed with the agreement of the patient. Hydrocortisone was given intravenously during the left partial adrenalectomy, and was maintained at a daily dose of $150-75 \mathrm{mg}$ for 5 days after the operation. The patient did not have any symptoms associated with adrenal insufficiency after the hydrocortisone supplementation discontinued. Ten days after left partial adrenalectomy, the patient's cortisol concentrations retained normal circadian variations and $0.5 \mathrm{mg}$ dexamethasone suppressed endogenous cortisol secretion (plasma total cortisol was $32 \mathrm{nmol} / \mathrm{L}$ at 08:00 the next day after $0.5 \mathrm{mg}$ overnight dexamethasone suppression test), which strongly supported that the resected left adrenocortical adenoma had been producing cortisol (Table 3). The rapid recovery of cortisol circadian might be explained by his Cushing's syndrome being mild and subclinical. However, the patient remained hypertensive $(165 / 118 \mathrm{mmHg})$ and hypokalemia (serum potassium was $1.98 \mathrm{mmol} / \mathrm{L}$, Table 1). Accordingly, after potassium supplement, saline infusion and captopril challenge tests were performed. The results revealed a high plasma aldosterone concentration and suppressed plasma renin activity (PRA), which supported the diagnosis of primary hyperaldosteronism (Table 2) [9]. Four days after endoscopic right partial adrenalectomy, the patient's blood pressure and serum potassium returned normal.

Pathological examination revealed that the left adrenal mass was a $3.0 \times 2.5 \times 2.3 \mathrm{~cm}$ golden-yellow adenoma, composed mainly of eosinophilic compact cells on hematoxylin/eosin (HE) stained sections (Fig. 2a), and the right adrenal tumor was a $2.0 \times 1.7 \times 1.5 \mathrm{~cm}$ and bright yellow adenoma, consisted of both clear and compact cells, with the former cell type being dominant (Fig. $2 \mathrm{~b})$. To understand the function of resected masses, we further performed immuno-histochemical analysis for steroidogenic enzymes. The left mass was found with diffused presence of 17alpha-hydroxylase1 (P450c17)

Table 3 Results of the Dexamethasone Suppression Tests

\begin{tabular}{|c|c|c|c|c|c|}
\hline & & $\begin{array}{l}\text { PTC-24 } \\
\text { (nmol/L) }\end{array}$ & $\begin{array}{l}\text { PTC-8 } \\
\text { (nmol/L) }\end{array}$ & $\begin{array}{l}\text { PTC-N8 } \\
\text { (nmol/L) }\end{array}$ & $\begin{array}{l}\mathrm{ACTH} \\
(\mathrm{ng} / \mathrm{L})\end{array}$ \\
\hline \multirow[t]{3}{*}{ Before operation } & Baseline & 146 & 346 & - & 17.82 \\
\hline & $1 \mathrm{mg}$ ODMST & - & - & 273 & 5.76 \\
\hline & Standard low-dose DMST & - & 274 & 274 & $<1.00$ \\
\hline \multirow[t]{2}{*}{ After left partial adrenalectomy } & Baseline & 63 & 305 & - & 38.16 \\
\hline & $0.5 \mathrm{mg}$ ODMST & 29 & - & 32 & 3.10 \\
\hline After right partial adrenalectomy & Baseline & - & 389 & - & 43.27 \\
\hline
\end{tabular}

ODMST overnight dexamethasone suppression test, DMST dexamethasone suppression test, PTC-24 plasma total cortisol at 24:00, PTC-8 plasma total cortisol at 08:00, PTC-N8 plasma total cortisol at next 08:00 after DMST, ACTH adrenocorticotropic hormone 


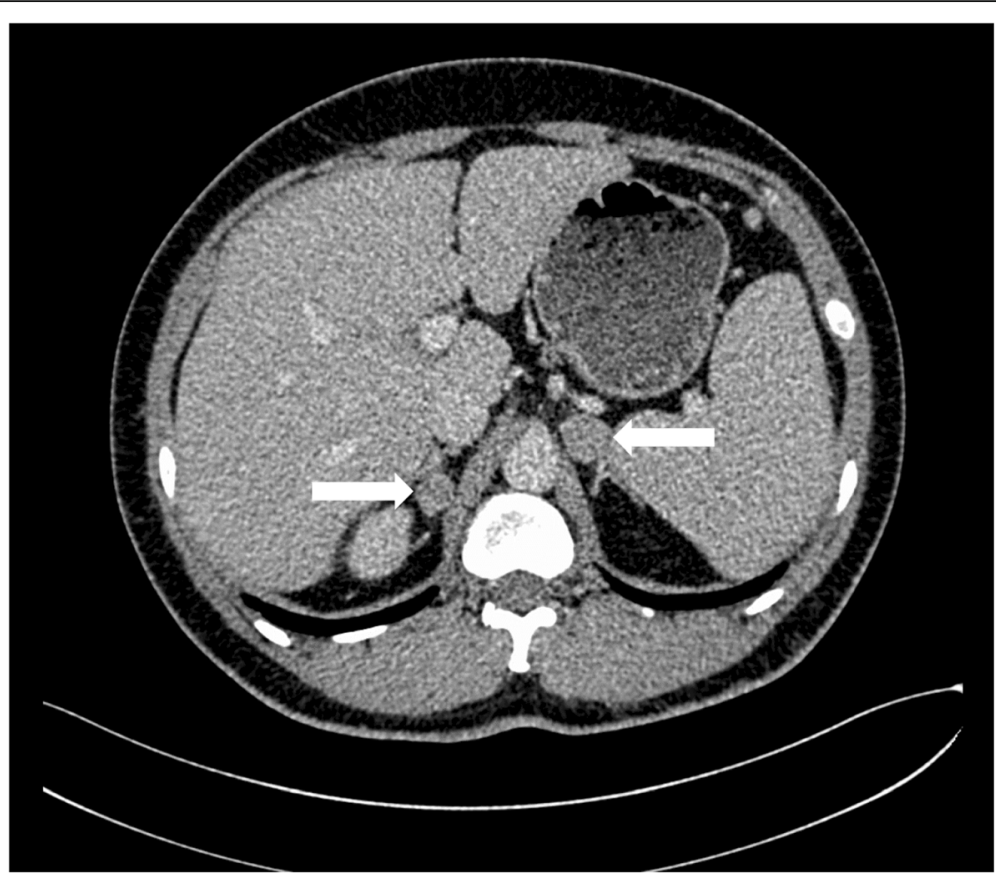

Fig. 1 Adrenal computed tomography (CT) image showing a $19 \times 14 \mathrm{~mm}$ right adrenal tumor and a $25 \times 15 \mathrm{~mm}$ left adrenal tumor (arrows)

(Fig. 2c) and local presence of 3b-hydroxysteroid dehydrogenase (3ß-HSD) (Fig. 2e) with no expression of 11beta-hydroxylase 2 (CYP11B2) (Fig. 2g). The right mass showed negative immunoreactivity to P450c17 (Fig. 2f) with increased homogenous immunoreactivity to $3 \beta-H S D$ and CYP11B2 (Fig. $2 \mathrm{~d}$ and $\mathrm{h}$, respectively). These immuno-histochemical results confirmed that the patient had a co-existing right aldosterone-producing adenoma and a left cortisol-producing adrenal adenoma.

His blood pressure and serum potassium remained normal one month after the sequential partial adrenalectomy, without any medication. The laboratory findings at the last follow-up compared to those upon admission are shown in Table 1.

\section{Review of published reports}

We searched PubMed for case reports of bilateral adenomas secreting different hormones independently till December 10, 2018, using the combinations of the following keywords: "Cushing's syndrome", "hypercortisolism",

Table 4 Results of adrenal venous sampling

\begin{tabular}{llll}
\hline & $\begin{array}{l}\text { Aldosterone } \\
(\mathrm{ng} / \mathrm{dL})\end{array}$ & $\begin{array}{l}\text { Cortisol } \\
(\mathrm{nmol} / \mathrm{L})\end{array}$ & $\begin{array}{l}\text { Epinephrine } \\
(\mathrm{ng} / \mathrm{L})\end{array}$ \\
\hline LAV & 42.34 & 7701 & 607 \\
RAV & $>200.00$ & 601 & 576 \\
IVC & 22.00 & 281 & 66 \\
LAV: RAV ratio (left/ right) & $<0.21$ & 12.81 & 1.05 \\
\hline
\end{tabular}

$A V$ adrenal vein, $I V C$ inferior vena cava "primary aldosteronism" and "bilateral adrenocortical adenoma". All references of included reports and relevant reviews were screened manually for additional potential eligible cases. The search was limited to full-text articles published in English.

Only five cases with bilateral functioning adenomas [10-14] were found. Among reported patients, all were hypertensive, four presented with hypokalemia [10-12, 14] and three had typical Cushingoid features [10, 12, 13]. It is noteworthy that only two patients presented with all three typical characteristics, namely hypertension, hypokalemia and Cushingoid features $[10,12]$. The diagnosis was made preoperatively based on results of AVS in all five patients and was confirmed by immunohistochemical staining for steroidogenic enzymes in only three [11-13]. Detailed information on each reported patients is presented in Additional file 1: Table S1, including name of first author, year of publication, country, patient characteristics (sex and age at diagnosis), symptoms, preoperative diagnostic technique, surgical operation, appearance of cut surface of tumor, and histopathological findings.

\section{Discussion}

We here present a case of bilateral adrenal adenomas, left of which produced cortisol and right produced aldosterone, as determined by AVS and confirmed by immunohistochemical analysis. Many reported cases of coexisting hypersecretion of cortisol and aldosterone were solitary or multiple adrenocortical adenomas that secrete 

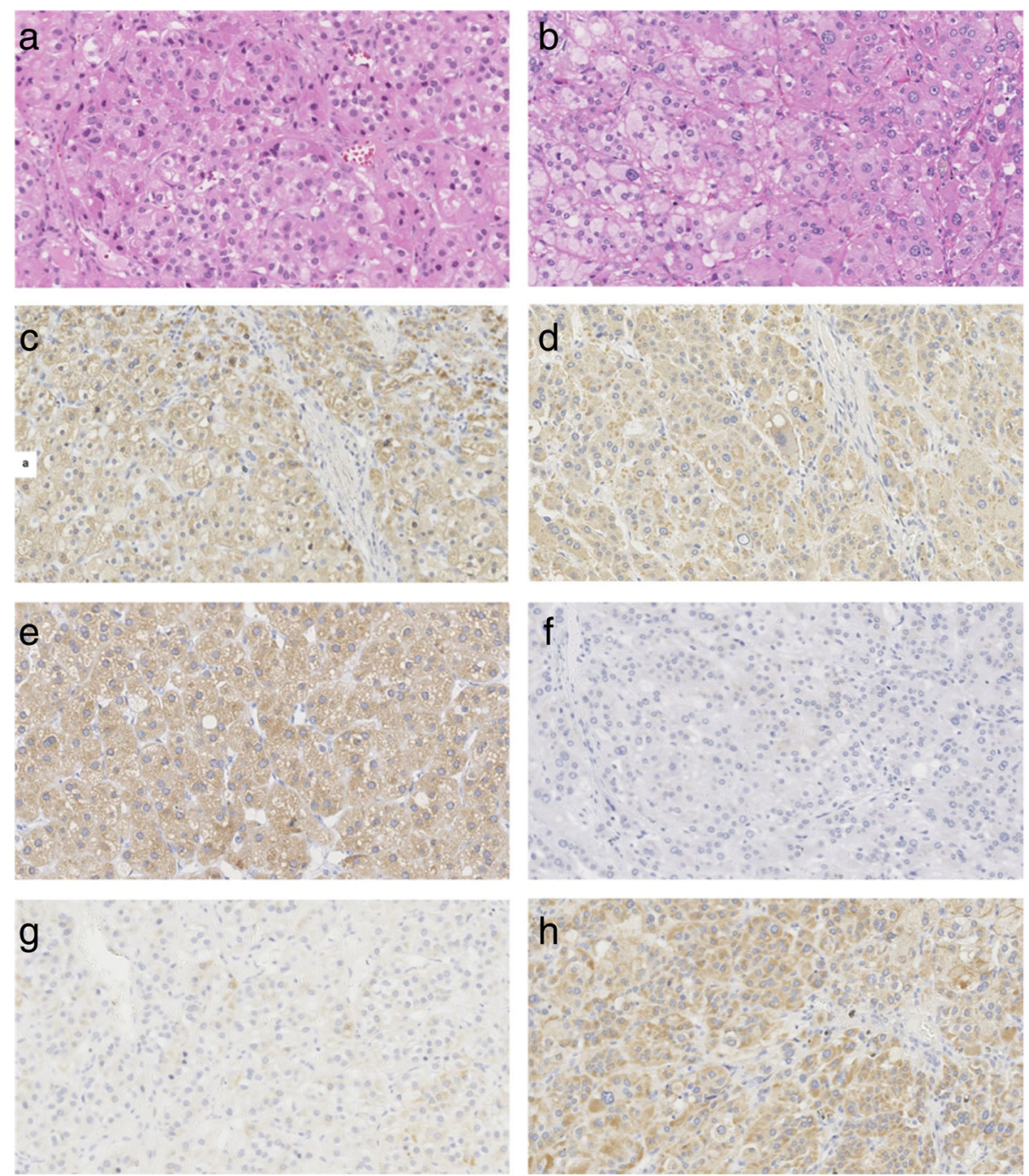

Fig. 2 Histological and immunohistochemical findings. (a, c, e, g) Left adrenal gland. (b, d, f, h) Right adrenal gland. (a). Photomicrograph of left adrenal mass showing it is composed mainly of eosinophilic compact cells (H\&E stain, $\times 200$ ). (b). Photomicrograph of right adrenal mass showing it consists of both clear and compact cells, the former type predominating (H\&E stain, $\times 200$ ). (c, d) Immunohistochemical demonstration of 33-HSD. (e, f) Immunohistochemical demonstration of P450c17. (g, h) Immunohistochemical demonstration of CYP1 1B2

both aldosterone and cortisol simultaneously as reviewed by Spath et al. [4]. However, it is extremely rare reported that multiple adrenocortical adenomas located bilaterally secrete different types of hormones from each side.

The presented patient did not have typical Cushingoid features or PA, which promoted a challenge in clinical practice to establish accurate diagnosis. Our review of similar cases suggested that this atypical manifestation was common among patients with co-existing hyperaldosteronism and hypercortisolism. The lacking of overt Cushingoid clinical features might be attributable to the secretion of cortisol remaining under adrenocorticotropic hormone $(\mathrm{ACTH})$ feedback control and circulating cortisol concentration being not high enough to induce overt Cushingoid features. Since PRA was measured by radioimmunoassay of generated angiotensin I, the failure of aldosterone to suppress renin, presented as a normal ARR that excluded our patient from further PA screening upon admission, might be caused by the interference from high plasma cortisol which could significantly increase plasma angiotensinogen level and consequently increase generated angiotensin I, leading to falsely increased PRA [15]. Guthrie and Kotchen reported a similar case with a unilateral adrenal adenoma producing both cortisol and aldosterone, in which renin was not suppressed by aldosterone [16], same as in this patient. Previous studies also found that the renin-angiotensinaldosterone system was affected by plasma ACTH concentration in patients with aldosterone-producing adenomas (APAs) [17-19]. As supported by a review of 35 
patients with aldosterone- and cortisol-co-secreting tumors by Spath et al., the atypical clinical manifestations and laboratory findings among these patients were likely to cause misinterpretation of diagnostic test results, if not dealt with caution [4].

Given that the coexistence of aldosterone and cortisol co-secreting adrenal tumors is not uncommon, we recommended that patients with suspected primary hyperaldosteronism should also be screened for hypercortisolism, and that a low-dose overnight dexamethasone suppression test was likely adequate for this purpose. Moreover, careful interpretation of laboratory results of the renin-angiotensin-aldosterone system is necessary, especially when secretion of endogenous $\mathrm{ACTH}$ is suppressed, as seen in our patient. Furthermore, for patients with bilateral adrenal cortical adenomas, if biochemical evidence suggests co-existing of hypercortisolism and hyperaldosteronism, regardless of Cushingoid clinical manifestations, AVS should be the gold standard for making a definitive diagnosis and for lateralizing functioning adrenocortical adenomas. However, the interpretation of AVS findings in these patients is also challenging, because the aldosterone to cortisol ratio, which was the most widely used measurement in clinical practice, was affected by the relative amount of cortisol and aldosterone secreted. To minimize misinterpretation, we also measured the concentrations of plasma epinephrine in both adrenal veins and inferior vena cava to enable adjustment in the present patient [20].

Aldosterone is synthesized in the ZG, the outermost zone of the adrenal cortex of humans, whereas glucocorticoids (cortisol and corticosterone) are produced in the ZF, the mid zone [21]. Aldosterone-producing adenomas (APAs) and cortisol-producing adenomas (CPAs) represent benign tumors of the ZG and the ZF, respectively. Nishimoto et al. described the expression patterns of steroidogenic enzymes in normal adrenal glands, APAs and CPAs, and summarized the steroidogenic enzymes that are responsible for adrenocortical hormone production,

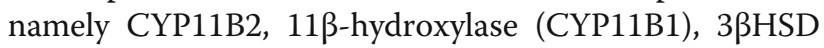
(upstream enzyme for both CYP11B2 and CYP11B1), and P450c17 (upstream enzyme for CYP11B1, but not for CYP11B2). In the ZG and APA, CYP11B2-positive cells co-express $3 \beta \mathrm{HSD}$ in the aldosterone synthetic pathway. In the ZF and CPA, CYP11B1-positive cells coexpress 3BHSD and P450c17, both of which are enzymes upstream of CYP11B1 in the cortisol synthetic pathway $[22,23]$. In this patient, we performed immunohistochemical analyses for CYP11B2, 33HSD, and P450c17 and found that he had a right adenoma that autonomously produced aldosterone and a left adenoma that autonomously produced cortisol, consistent with the results of AVS. Immunohistochemistry has become an important tool for the diagnosis of adrenocortical pathological conditions, and is sometimes an indispensable step in confirming the diagnosis.

\section{Conclusions}

In summary, we presented an extremely rare case of bilateral adrenal adenomas, the left of which secreted cortisol and the right of which secreted aldosterone, as determined by AVS and confirmed by histopathological evaluation of the resected surgical specimens, including immunohistochemical evaluation of steroidogenic enzymes. We suggested that patients with bilateral adrenal adenomas should be screened for both hyperaldosteronism and hypercortisolism to minimize misdiagnoses. AVS, with proper interpretations, is essential in such patients, and immunohistochemistry might become a widely used and powerful tool for identifying aldosterone/cortisol-producing lesions in close future.

\section{Additional file}

Additional file 1: Table S1. The available case reports of with bilateral adrenocortical adenomas secreting cortisol or aldosterone independently. A/CPA, aldosterone- and cortisol-producing adenoma; APA, aldosteroneproducing adenoma; ARR, aldosterone-to-renin ratio; AVS, adrenal venous sampling; BPA, Bilateral partial adrenalectomy; CPA, cortisol-producing adenoma; CS, Cushing's syndrome; HE, hematoxylin-eosin stain; $I H C$, Immunohistochemical; LPA, Left partial adrenalectomy; LTA, Left total adrenalectomy; NM, not mentioned; PAC, plasma aldosterone concentration; PRA, plasma renin activity; RPA, Right partial adrenalectomy; RTA, Right total adrenalectomy. (DOCX 24 kb)

\section{Abbreviations}

24 h UFC: Twenty-four-hour urine free cortisol; 3ß-HSD: 3b-hydroxysteroid dehydrogenase; ACTH: Adrenocorticotropic hormone; APA: Aldosteroneproducing adenoma; ARR: Aldosterone-to-renin ratio; AV: Adrenal vein; AVS: Adrenal venous sampling; CPA: Cortisol-producing adenoma; CS: Cushing's syndrome; CT: Computed tomography; CYP11B1: 11ßhydroxylase; CYP11B2: 11 beta-hydroxylase 2; HbA1c: glycosylated hemoglobin; IVC: Inferior vena cava; P450c17: 17alpha-hydroxylase1; PA: Primary aldosteronism; PAC: Plasma aldosterone concentration; PRA: Plasma renin activity; SCS: Subclinical Cushing's syndrome; ZF: Zona fasciculate; ZG: Zona glomerulosa; ZR: Zona reticularis

\section{Acknowledgments}

We thank Dr. Trish Reynolds, MBBS, FRACP, from Liwen Bianji, Edanz Group China (www.liwenbianji.cn/ac), for editing the English text of a draft of this manuscript.

\section{Authors' contributions}

$K R$ and $J L$ diagnosed and treated the patient, reviewed the literature and drafted the manuscript. YZ and NW performed the surgery and helped draft the manuscript. YT carried out the pathological diagnosis and helped draft the manuscript. JW, QLL, QZ, YY and ZA participated in the clinical diagnosis and treatments, and helped draft the manuscript. QRL and JC gave suggestions and helped draft the manuscript. JL critically revised the manuscript. All of the authors read and approved the final manuscript.

\section{Funding}

This research was supported by the grant from Science and Technology Department of Sichuan Province (Grant No. 2018HH0065). 


\section{Availability of data and materials}

Data sharing is not applicable to this article as no datasets were generated or analyzed during the current study.

\section{Ethics approval and consent to participate}

This case study was approved by the West China Hospital of Sichuan University Biomedical Research Ethics Committee and the consent to participate was waived. The ethics approval number is 2019-158.

\section{Consent for publication}

Written informed consent for publication of the patient's clinical details and clinical images was obtained from the patient and his relatives.

\section{Competing interests}

The authors declare that they have no competing interests.

\section{Author details}

'Department of Endocrinology and Metabolism, West China Hospital, Sichuan University, Chengdu 610041, China. ${ }^{2}$ Department of Urology, West China Hospital, Sichuan University, Chengdu 610041, China. ${ }^{3}$ Department of Pathology, West China Hospital, Sichuan University, Chengdu 610041, China. ${ }^{4}$ Department of Pathology, Immunology, and Laboratory Medicine, University of Florida, Gainesville, FL 32610, USA.

Received: 13 January 2019 Accepted: 10 June 2019

Published online: 17 June 2019

\section{References}

1. Xing Y, Lerario AM, Rainey W, Hammer GD. Development of adrenal cortex zonation. Endocrinol Metab Clin N Am. 2015;44(2):243-74.

2. Galati SJ. Primary aldosteronism: challenges in diagnosis and management. Endocrinol Metab Clin N Am. 2015:44(2):355-69.

3. Newell-Price J, Bertagna X, Grossman AB, Nieman LK. Cushing's syndrome. Lancet. 2006:367(9522):1605-17.

4. Späth M, Korovkin S, Antke C, Anlauf M, Willenberg HS. Aldosterone- and cortisol-co-secreting adrenal tumors: the lost subtype of primary aldosteronism. Eur J Endocrinol. 2011;164(4):447-55.

5. Kukidome D, Miyamura N, Sakakida K, Shimoda S, Shigematu Y, Nishi K, et al. A case of cortisol producing adrenal adenoma associated with a latent aldosteronoma: usefulness of the ACTH loading test for the detection of covert aldosteronism in overt Cushing syndrome. Intern Med. 2012;51(4): 395-400.

6. Vicennati V, Repaci A, Di DG, Rinaldi E, Golfieri R, Giampalma E, et al. Combined aldosterone and cortisol secretion by adrenal incidentaloma. Int J Surg Pathol. 2012;20(3):316-9.

7. Inagaki Y, Uemura M, Nakata W, Nakai Y, Takayama H, Tsujimura A, et al. Subclinical Cushing's syndrome with primary aldosteronism with the developing symptom of complications : a case report. Hinyokika Kiyo. 2013; 59(11):719-22.

8. Chang KY, Ryu S, Cho JY, Kim HW. Aldosterone- and cortisol-co-producing adrenal adenoma without clinical features of Cushing syndrome. Korean $J$ Intern Med. 2014;29(5):679-82.

9. Funder JW, Carey RM, Mantero F, Murad MH, Reincke M, Shibata H. The management of primary aldosteronism: case detection, diagnosis, and treatment: an endocrine society clinical practice guideline. J Clin Endocrinol Metab. 2016;101(5):1889-916.

10. Nagae A, Murakami E, Hiwada K, Kubota O, Takada Y, Ohmori T. Primary aldosteronism with cortisol overproduction from bilateral multiple adrenal adenomas. Jpn J Med. 1991;30(1):26-31.

11. Oki K, Yamane K, Sakashita Y, Kamei N, Watanabe H, Toyota N, et al. Primary aldosteronism and hypercortisolism due to bilateral functioning adrenocortical adenomas. Clin Exp Nephrol. 2008:12(5):382-7.

12. Onoda N, Ishikawa T, Nishio K, Tahara H, Inaba M, Wakasa K, et al. Cushing's syndrome by left adrenocortical adenoma synchronously associated with primary aldosteronism by right adrenocortical adenoma: report of a case. Endocr J. 2009;56(3):495-502

13. Morimoto R, Kudo M, Murakami O, Takase K. Ishidoya, Nakamura Y, et al. difficult-to-control hypertension due to bilateral aldosterone-producing adrenocortical microadenomas associated with a cortisol-producing adrenal macroadenoma. J Hum Hypertens. 2011;25(2):114-21.
14. Lee SE, Kim JH, Lee YB, Seok H, Shin IS, Eun YH, et al. Bilateral adrenocortical masses producing aldosterone and cortisol independently. Endocrinol Metab (Seoul). 2015;30(4):607-13.

15. KRAKOFF LR. Measurement of plasma renin substrate by radioimmunoassay of angiotensin I: concentration in syndromes associated with steroid excess. J Clin Endocrinol Metab. 1973;37(1):110-7.

16. Jr GG, Kotchen TA. Hypertension and aldosterone overproduction without renin suppression in Cushing's syndrome from an adrenal adenoma. Am J Med. 1979;67(3):524-8.

17. Stowasser M, Klemm SA, Tunny TJ, Gordon RD. Plasma aldosterone response to ACTH in subtypes of primary aldosteronism. Clin Exp Pharmacol Physiol. 1995;22(6-7):460-2.

18. Vetter $H$, Berger $M$, Armbruster $H$, Siegenthaler W, Werning $C$, Vetter W. Episodic secretion of aldosterone in primary aldosteronism: relationship to cortisol. Clin Endocrinol. 1974:3(1):41-8.

19. Terzolo M, Pia A, Reimondo G. Subclinical Cushing's syndrome: definition and management. Clin Endocrinol. 2012;76(1):12-8.

20. Young WF, Plessis HD, Thompson GB, et al. The clinical conundrum of Corticotropin-independent autonomous cortisol secretion in patients with bilateral adrenal masses. World J Surg. 2008;32(5):856-62.

21. Nishimoto K, Koga M, Seki T, Oki K, Gomezsanchez EP, Gomezsanchez CE, et al. Immunohistochemistry of aldosterone synthase leads the way to the pathogenesis of primary aldosteronism. Mol Cell Endocrinol. 2017;441:12433.

22. Nishimoto K, Nakagawa K, Li D, Kosaka T, Oya M, Mikami S, et al. Adrenocortical zonation in humans under normal and pathological conditions. J Clin Endo Metab. 2010;95(5):2296-305.

23. Hattangady NG, Olala LO, Bollag WB, Rainey WE. Acute and chronic regulation of aldosterone production. Mol Cell Endocrinol. 2012;350(2):15162.

\section{Publisher's Note}

Springer Nature remains neutral with regard to jurisdictional claims in published maps and institutional affiliations.

Ready to submit your research? Choose BMC and benefit from:

- fast, convenient online submission

- thorough peer review by experienced researchers in your field

- rapid publication on acceptance

- support for research data, including large and complex data types

- gold Open Access which fosters wider collaboration and increased citations

- maximum visibility for your research: over $100 \mathrm{M}$ website views per year

At BMC, research is always in progress.

Learn more biomedcentral.com/submissions 